\title{
Examining the Satisfaction Level of Construction Workers Regarding Safety Management in the Kingdom of Saudi Arabia
}

\author{
*Subashini Suresh, Suresh Renukappa, Ibrahim Alghanmi, Sabah \\ Mushatat and Raymond Olayinka
}

Published online: 30 August 2017

To cite this article: Subashini Suresh, Suresh Renukappa, Ibrahim Alghanmi, Sabah Mushatat and Raymond Olayinka. (2017). Examining the satisfaction level of construction workers regarding safety management in the Kingdom of Saudi Arabia. Journal of Construction in Developing Countries, 22(1): 97-113. https://doi.org/10.21315/jcdc2017.22.1.6

To link to this article: https://doi.org/10.21315/jcdc2017.22.1.6

Abstract: The importance of the construction industry in Saudi Arabia cannot be overemphasised, as it provides the infrastructure required for other sectors of the economy to grow, thus reflecting the level of economic development in the country. However, in Saudi Arabia, the construction industry is among the most hazardous, with a high level of accidents and fatalities. This study examines health and safety practices in the construction industry of Saudi Arabia and identifies opportunities for improvement. It also discusses the safety climate. The study adopted a quantitative approach in which a survey questionnaire was distributed and returned at a $60 \%$ response rate. The survey data were analysed using descriptive statistics with SPSS statistical software. The findings show that the Saudi Arabia construction industry has made improvements in health and safety standards; however, there are opportunities for further improvement. There are on-going efforts to maintain reasonable health and safety standards for employees on-site, but conditions off-site, particularly those of migrant employees on fixed-term labour contracts, are difficult. Unpaid wages and lack of welfare facilities contribute to physical and psychological stresses that are linked to impaired on-site performance, lack of motivation, lack of productivity and a lack of interest in adhering to health and safety guidelines. The study concludes that it is possible to improve health and safety in the construction industry through the effective enforcement of existing health and safety laws, enacting legislation regarding off-site health and safety for migrant workers, maintaining a fund for social security, and improving the regulation of commercial and contractual transactions. This study contributes to the knowledge of government policy and decision making in implementing health and safety regulations in the construction industry.

Keywords: Health and safety practices, Kingdom of Saudi Arabia, Safety climate and welfare

\section{INTRODUCTION}

The construction industry is both economically and socially important. It provides the infrastructure required for the economy to grow, thus reflecting the level of economic development of the country (Cole and Lorch, 2003; Hasan, 2011). However, the construction industry is also recognised to be hazardous (Farooqui, Arif and Rafeeqi, 2008). In Saudi Arabia, the construction industry is classified as a high-risk industry, with a high level of accidents and fatalities. The Saudi construction sector provides employment for over one million workers and accounts for almost $14.4 \%$ of the country's 7.3 million-person labour force

University of Wolverhampton, Wulfruna Street, Wolverhampton, UNITED KINGDOM ${ }^{*}$ Corresponding author: S.Subashini@wlv.ac.uk

(C) Penerbit Universiti Sains Malaysia, 2017. This work is licensed under the terms of the Creative Commons Attribution (CC BY) (http://creativecommons.org/licenses/by/4.0). 
(Ramady, 2010). Many of those who work in construction confront dangerous working environments and exploitative work practices. The role of health and safety is to address both the physical and psychological well-being of workers on construction sites and other persons whose health is likely to be adversely affected by construction activities (Dryzek and Schlosberg, 2005).

Because of the high accident rate in the construction industry, the Ministry of Labour introduced Safety Management Regulations on 24 November 1999 that are applicable to the construction industry (Saudi Ministry of Labour, 2000). Unfortunately, the enforcement of safety regulations is not widespread. The industry is characterised by lax implementation of commercial and contractual laws. The traditional approach to solving problems related to labour shortages is to recruit fixed-term contract labour as cheaply as possible from underdeveloped nations rather than create a permanent labour pool. As a result, there is a critical need for sustained and continuous improvement in health and safety in the construction industry. This study therefore aims to examine health and safety practices of the construction industry in Saudi Arabia and to identify means of facilitating improvements within these practices. To address these aims, the following objectives were established:

1. To examine the concept and importance of health and safety in the construction industry, including existing regulations, policies and measures through a critical review of the literature.

2. To investigate perceptions and attitudes regarding health and safety at Saudi Arabia construction sites by conducting a questionnaire survey with workers and managers.

3. To analyse data from the responses to the questionnaire survey to determine industry trends regarding health and safety practices in the construction industry in Saudi Arabia.

4. To discuss and conclude how to best improve health and safety in the Saudi Arabia construction industry.

\section{LITERATURE REVIEW}

According to Hughes and Ferrett (2016), the term 'safety' refers to an absence of danger and is often partnered with the term 'health' within the context of work in general, including construction work. Because health and welfare are of concern to society, an employer has a responsibility to ensure that there are minimal risks to the health and safety of employees so that individuals, families and society at large can receive protection and remain free from injuries and fatalities. There is global concern for health and safety in construction, and many nations have enacted laws and regulations to emphasise health and safety in various occupations based on recommendations of international organisations, including the International Labour Organisation (ILO) (Coble, Haupt and Hinze, 2000). Therefore, a need exists to ensure that these laws and regulations are effective and practical.

Research presented by Jannadi and Assaf (1998) suggests that the safety and health of construction workers have always been important in Saudi Arabia. The larger and more professional organisations in Saudi Arabia, including firms such 
as Saudi Aramco and Saudi Basic Industries Corporation (SABIC), emphasise excellence in worker health and safety, but smaller construction firms perform relatively poorly (Jannadi and Al-Sudairi, 1995; Jannadi and Assaf, 1998). Jannadi and Assaf (1998) called for the enactment of a safety code for the construction sector in Saudi Arabia. This was apparently implemented in collaboration with the International Code Council for safety in construction (IHS Construction Solutions, 2007). However, even if laws and regulations for health and safety exist, they are not always implemented efficiently to effectively address the problems that they were designed to solve. Although precise and comprehensive statistics for safety and health in the Saudi Arabia construction industry are lacking, Jannadi and BuKhamsin (2002) suggest that even in Saudi Arabia, organisations involved in construction cannot avoid responsibility for safety because construction activities occur on their sites. Jannadi and Bu-Khamsin (2002) conclude that a consensus exists amongst construction contractors in Saudi Arabia that management involvement, personal protective equipment, and emergency disaster planning and preparation are essential for construction safety, but nationwide statistics related to construction safety and health are lacking.

Baig (2001) presents a discussion on construction safety in the Eastern Province of Saudi Arabia, with the frequencies of injury and accidents in selected firms reported based on a survey. Nevertheless, there are no authoritative data available from the government of Saudi Arabia that measure injury and deaths in the construction sector. Thus, if the government does not maintain statistics for injuries, accidents and deaths, enforcing regulatory action will be difficult.

The Basic Law of Governance document of Saudi Arabia clearly states that the basis of government is a premise of justice, consultation and equality in accordance with Islamic Shari'ah law (Middle East Info, 2011). Chapter 8 of the Saudi Labour Law addresses the "Protection Against Occupational Hazards, Major Industrial Accidents and Work Injuries, and Health and Social Services" in the Kingdom. It is possible to sue an employer who has been negligent in adequately providing for an employee in a Saudi Labour or Shari'ah court (Gulf Talent, 2008). A comprehensive social security and benefit system exists for those who are nationals of Saudi Arabia, but migrant workers are not entitled to receive protection under this system because the governments of the countries of which they are citizens must look after them (World Law Guide, 2010). Although the government has attempted to ensure that an obligation exists on the part of all those involved in construction to ensure safety and health, there are always opportunities for improvement.

It is clear that construction safety legislation and its enforcement are important for enhancing health and safety in the construction industry. Even more crucial is how to effectively implement and enforce those laws. The safety and health provisions enshrined in the Saudi Labour Law is fair and comprehensive (O'Kane, 2010; Ministry of Labour, Kingdom of Saudi Arabia, 2011). The Saudi Labour Law requires employers to maintain the workplace in a clean and hygienic condition and to comply with other rules, measures and standards of occupational protection, and health and safety in accordance with the Minister's decisions. However, it is pertinent to ask if this requirement extends to the living quarters of workers sponsored by an employer to work in Saudi Arabia because most complaints are about the living quarters of sponsored workers. The Saudi Labour Law stipulates that employers take the necessary precautions to protect 
workers against occupational diseases, hazards and to provide work safety and protection. Employers must post instructions related to work in a language that the workers understand at prominent locations, and they must inform workers about hazards associated with their work. Article 123 of Part VIII of the Saudi Labour Law requires the provision of protective equipment and appropriate personal gear as well as the training of workers to avert hazards. Article 124 obliges workers to use this protective gear to ensure safety. Article 125 requires employers to take precautions against fires and Article 126 obligates employers to act appropriately to protect all those who are not employees but who must enter work locations. Articles 132-144, Part VIII of the Saudi Labour Law highlights work injuries and occupational diseases that workers may acquire unintentionally while working for an employer (Ministry of Labour, Kingdom of Saudi Arabia, 2011, see especially Labour Law - Part VIII). Those with work injuries or occupational diseases must receive treatment at the expense of the employer with full pay for the first 30 days and then at $75 \%$ of their salary for the duration of treatment.

Apart from health and safety legislation, it is important to know why construction accidents occur to help improve accident prevention. Poor safety management and the failure to control risk during construction activities may lead to accidents or injuries. Effective safety management is essential to prevent accidents and deaths. Safety contributes to productivity because in a safe work environment, workers are able to focus on their jobs. The major causes of accidents have been identified and can be attributed either to unsafe design or site practices. Accidents can arise from different causes, which can generally be classified as physical incidents posing hazardous situations and behavioural incidents caused by unsafe acts (Kartam 1997). Thus, an underlying belief is that accidents are not entirely caused by careless workers but sometimes occur due to failure in control, which is ultimately the responsibility of the management. Debobbeleer and Beland (1991) reviewed the safety climate and noted that management commitment and worker involvement were the two most important factors. Flin et al. (2000) reviewed 18 sources and determined that the common features of a safety climate are related to management, safety systems and risk. This raises the question of what a safety climate is.

\section{Safety Climate}

The term safety climate was introduced by Zohar (1980) in his research study. He defined safety climate as "a summary of molar perceptions that employees share about their work environments." Following a popular theory, he argued that these perceptions serve as a frame of reference within which employees behave. Zohar (1980) concluded that management needs to change its attitude and increase its commitment to safety to improve the safety level of the organisation. He also suggested that a safety climate survey is a practical tool to compare safety performance between organisations because it is independent of factors such as technologies and risk levels, which have caused difficulties in measuring safety performance in the past. Zohar's work has gained wide recognition, and many research studies have been conducted to further investigate the concept of safety climate. Definitions of safety climate that have been proposed are listed in Table 1.

100/PENERBIT UNIVERSITI SAINS MALAYSIA 
Table 1: Definitions of Safety Climate

\begin{tabular}{|c|c|}
\hline Author(s) & Definition \\
\hline $\begin{array}{l}\text { Brown \& Holmes } \\
\text { (1986) }\end{array}$ & $\begin{array}{l}\text { A set of perceptions or beliefs held by an individual and/or group } \\
\text { about a particular entity [which in this case is safety]. }\end{array}$ \\
\hline $\begin{array}{l}\text { Dedobbeleer \& } \\
\text { Béland (1991) }\end{array}$ & Molar perceptions people have of their work settings. \\
\hline $\begin{array}{l}\text { Coyle, Sleeman \& } \\
\text { Adams } \\
\text { (1995) }\end{array}$ & $\begin{array}{l}\text { The objective measurement of attitudes and perceptions towards } \\
\text { occupational health and safety issues. }\end{array}$ \\
\hline $\begin{array}{l}\text { Williamson et al. } \\
\text { (1997) }\end{array}$ & $\begin{array}{l}\text { A summary concept describing the safety ethic in an organisation or } \\
\text { workplace that is reflected in employees' beliefs about safety and is } \\
\text { thought to predict the way employees behave with respect to safety } \\
\text { in that workplace. }\end{array}$ \\
\hline Mohamed (2002) & $\begin{array}{l}\text { A construct that captures employees' perceptions of the role that } \\
\text { safety plays within the organisation [and] a descriptive measure } \\
\text { reflecting the workforce's perception of, and attitudes towards, } \\
\text { safety within the organisational atmosphere at a given point in time. }\end{array}$ \\
\hline $\begin{array}{l}\text { Cooper \& Phillips } \\
\text { (2004) }\end{array}$ & $\begin{array}{l}\text { Shared employee perceptions of how safety management is being } \\
\text { operationalised in the workplace at a particular moment in time. }\end{array}$ \\
\hline $\begin{array}{l}\text { Hahn \& Murphy } \\
\text { (2008) }\end{array}$ & $\begin{array}{l}\text { Shared perceptions of employees about the safety of their work } \\
\text { environment. }\end{array}$ \\
\hline $\begin{array}{l}\text { Neale \& Waters } \\
(2012)\end{array}$ & $\begin{array}{l}\text { Workers' safety values, attitudes and perceptions are part of the } \\
\text { psychological elements of safety culture. }\end{array}$ \\
\hline
\end{tabular}

Although the list of definitions given in Table 1 may not be exhaustive, there are similarities that can be drawn between them. First, all authors concur that the safety climate represents employees' perceptions and attitudes towards safety in the organisation or their workplace. Second, safety climate only measures perceptions and attitudes towards safety at a certain point in time, that is, during the time when the survey is conducted. This characteristic indicates that safety climate may change over time; thus, it is important to measure safety climate regularly to identify trends and problem areas that need to be addressed (Zou \& Sunindijo, 2010). Third, it is important to recognise levels of aggregation of safety climate. There may be more than one level of safety climate in an organisation, such as an organisational-level safety climate and workplace-level safety climate. A study of a multilevel model of safety climate was conducted by Zohar and Luria (2005). They used two questionnaires that were administered to production workers in manufacturing plants. The first questionnaire measured organisation-level safety climate, whilst the second measured group-level safety climate. The results showed that at both levels, the climates were globally aligned, meaning that the organisational climate predicts the group climate level, which, in turn, predicts individual behaviour.

Research studies conducted by Davies, Spencer and Dooley (2001), Mohamed (2002), Seo et al. (2004) and Hahn and Murphy (2008) on safety climate have focused on the following four areas:

1. Developing safety climate measurement tools and determining safety climate dimensions. 
2. Developing and testing a theoretical model of safety climate to discover factors that affect safety behaviour and accidents.

3. Finding the relationship between safety climate and safety performance.

4. Investigating the relationship between safety climate and organisational climate.

Guldenmund (2000) noted there are six dimensions of safety climate that should be measured: top management commitment, supervisors' involvement, safety training, communication, employees' involvement and safety rules. In this study, the focus is on the supervisors'/managers' and employees' involvement in health and safety practices in the Saudi Arabia construction industry.

\section{METHODOLOGY}

The study adopted a quantitative research approach (Creswell, 2014) to examine the health and safety practices of the Saudi Arabia construction industry. The use of the questionnaire method saves time and provides a reliable approach for obtaining quantitative data; it is considered to be a key method among researchers in management (Zikmund, 2000). A questionnaire was designed for data collection and analysis based on the themes that emerged from the review of the relevant literature.

Sampling is of critical importance in research, since in most cases, there is a larger population, and due to numerous restrictions, sampling is the only viable option for obtaining reliable responses that represent the views of this wider population. Sampling methods include two main categories (probability and nonprobability-based samples), and in each category, there are a number of techniques to select the most suitable sample for the given research (Wilson, 2010; Bryman and Bell, 2011 ; Saunders, Philip and Thornhill, 2012; Bryman, 2012).

Sample size determination is an important and often difficult step in planning a survey or empirical study because it is not possible to approach the whole population (Dattalo, 2008). Such an effort is likely to become prohibitively expensive, but it is also desirable to maintain accuracy and reliability to ensure that the survey results reflect reality with minimum error. Confidence intervals $(\mathrm{Cl})$ are useful for deciding on sample size because a $\mathrm{Cl}$ is a range of values around which a population parameter (e.g., true mean) is likely to lie in the long run (Dattalo, 2008). As an example, if samples of the same size are drawn repeatedly from a population after assuming a normal distribution for spread, and a $95 \% \mathrm{Cl}$ is calculated around each sample's mean (i.e., plus or minus two standard errors from the mean), then $95 \%$ of these intervals should contain the population mean.

A sample size calculator is available online from Creative Research Systems (2011), and this simplifies the process of calculating the sample size for a given $\mathrm{Cl}$ and confidence level, as described in Dattalo (2008). The number of construction firms working in the Kingdom of Saudi Arabia listed on the Saudi site of Findouter.com (2010) is approximately 80 . This means that for a confidence level of $95 \%$ and a $\mathrm{Cl}$ of $10 \%$, responses from 44 construction firms are required.

The questionnaire was administered to construction workers and managers in the Saudi Arabia construction industry using probability sampling of the Saudi Arabia construction companies listed on the web-based database Findouter.com. A total of 150 questionnaires were distributed to 44 construction 
firms, of which 90 were completed and returned with a $60 \%$ response rate. Of these, 30 responses were from managers and the rest from workers on site. The survey data were analysed using descriptive statistics with SPSS statistical software. The unit of analysis adopted for this study is the 'organisation,' and the embedded unit is 'individual employee.' The questionnaire was designed to examine health and safety practices on construction sites and to identify ways to facilitate improvements within the practices.

The questionnaire had five parts. The first part asked about background information; the second part addressed health and safety practices at the construction site; the third part asked about the effectiveness of the health and safety management system; the fourth part asked questions about the effectiveness of the Saudi Labour Law and its implementation for improving health and safety on construction sites; and lastly, the fifth part included questions about accommodation, meals and living conditions after work that influenced work performance/attitudes on construction sites, including those that affect health and safety.

\section{FINDINGS}

The relative size of the construction companies varied significantly. The annual income of the companies in the sample ranged from SR20 million to SR 10 billion. Other characteristics indicative of company size are the number of field workers employed, the number of jobs in progress and the number of field worker working hours. Over $50 \%$ of the companies reported that they had 300 or fewer field workers. The total average number of field workers was approximately 1,400. Some firms have a small field worker-to-revenue ratio, indicating that either a large portion of the work is subcontracted or much of the revenue is earned through management services. The typical number of projects in progress ranged from 5 to 700.

Respondents were first asked if there are designated full-time health and safety officers on their construction sites. A total of $20 \%$ of them responded that they had designated health and safety officers. An additional $30 \%$ responded that they often have designated health and safety officers while $30 \%$ responded that they rarely have them. Additionally, $20 \%$ of the respondents never had designated health and safety officers on site. Although health and safety supervisors are appointed, in some cases, they are not full-time staff but are assigned safetyrelated duties in addition to other work that they must perform as a part of their contract.

Respondents were asked to rate their level of satisfaction with health and safety practices on their construction sites using a 4-point Likert scale that was calibrated as follows: 1 = very satisfied, 2 = satisfied, $3=$ less than satisfied and $4=$ very disappointed. A total of 37 practices (see Table 2 ) relating to health and safety were extracted from the Saudi Labour Law document examined in the literature review. They included the measures taken on construction sites for the personal protection of workers such as the use of safety helmets, protective footwear, gloves, earplugs, safety goggles and facemasks. They also included the attitudes of the respondents towards health and safety, and their perception on the effectiveness of health and safety management systems on their construction sites. 
Table 2: Health and Safety Practices

\begin{tabular}{|c|c|}
\hline Health and Safety Practices On-Site & $\begin{array}{l}\text { Mean Rating of Level } \\
\text { of Satisfaction }\end{array}$ \\
\hline 1. PPE - Safety helmets & 2.4 \\
\hline 2. PPE - Protective footwear & 2.4 \\
\hline 3. PPE - Gloves & 2.4 \\
\hline 4. PPE - Safety goggles & 2.4 \\
\hline 5. PPE - Face masks & 2.4 \\
\hline 6. Attitude of workers to PPE usage & 2.4 \\
\hline 7. Attitude of management to PPE & 2.4 \\
\hline 8. Housekeeping & 2.7 \\
\hline 9. Openings/holes & 2.7 \\
\hline 10. Materials stored safely & 2.7 \\
\hline 11. Working at heights & 2.7 \\
\hline 12. Tools and machines not stored & 2.7 \\
\hline 13. Walkways & 2.7 \\
\hline 14. Safety mesh for excavation & 2.7 \\
\hline 15. Arrangements involving scaffolding & 2.0 \\
\hline 16. Availability of scaffolding boards & 2.0 \\
\hline 17. Availability of toe boards & 2.0 \\
\hline 18. Safety orientation & 2.0 \\
\hline 19. Ways workers approach challenges & 2.1 \\
\hline 20. Secure use of ladders & 2.1 \\
\hline 21. Mobile work platforms & 2.1 \\
\hline 22. Emphasis on health and safety & 2.8 \\
\hline 23. Satisfaction with site inspection by the Saudi ministry & 2.9 \\
\hline 24. Quality meals provided on-site & 2.4 \\
\hline 25. Measures taken to prevent accidents & 2.8 \\
\hline 26. Signage to indicate danger & 2.8 \\
\hline 27. Satisfaction of medical assistance & 2.8 \\
\hline 28. Availability of first aid kits & 2.8 \\
\hline 29. Availability of trained nurses & 2.8 \\
\hline 30. Satisfaction with accident rate & 2.3 \\
\hline 31. Prevalence of unsafe acts on-site & 2.9 \\
\hline 32. Level of unsafe conditions & 2.9 \\
\hline 33. Effectiveness of safety management system & 2.7 \\
\hline 34. Implementation of Saudi Labour Law to reduce accidents & 2.1 \\
\hline $\begin{array}{l}\text { 35. Implementation of Saudi Labour Law to enhance project } \\
\text { performance }\end{array}$ & 2.7 \\
\hline $\begin{array}{l}\text { 36. Satisfaction of safety management system to cause } \\
\text { improvements }\end{array}$ & 2.8 \\
\hline 37. Satisfaction with the capacity of Saudi Labour Law & 2.4 \\
\hline
\end{tabular}

Note: PPE = personnel protective equipment 
The mean rating for PPE-related practices was found to be 2.4 (Table 2). The mean rating for practices such as housekeeping, material storage and working on heights was found to be 2.7, while that for scaffolding and related practices was found to be 2 .

Figure 2 shows the further 16 practices that were rated by the respondents. Of the respondents, $70 \%$ stated that they were less than satisfied with the emphasis on health and safety presented by construction site management, including worker training and communication emphasising health and safety, and $40 \%$ of the respondents replied that they were less than satisfied with the accident rate on their construction site, including both small and large accidents. In contrast, $30 \%$ of respondents stated that they were very satisfied with the accident rate for their construction site. A total of $60 \%$ of respondents were less than satisfied with the prevalence of unsafe acts that could present dangers involving safety and health on their construction sites. The majority of respondents were less than satisfied with the effectiveness of the safety management system and the implementation of safety, health and labour standards of the Saudi Labour Law in increasing worker morale, worker awareness of site health and safety and improving worker behaviour.

When asked how satisfied the respondents were with the effectiveness of the safety management system at their construction sites and the implementation of the Saudi Labour Law to cause an overall reduction in costs related to accidents at the construction site (e.g., reduction in employee compensation, reduction in damage to equipment and tools, reduction in insurance premiums and reduction in time lost due to accidents and accident investigation), $40 \%$ were very satisfied, compared to $30 \%$ who were less than satisfied.

Respondents were asked closed-ended questions about the quality of their accommodations, meals and living conditions after work that influence their work performance and attitudes, including health and safety. Most workers live under difficult conditions off-site, without access to decent meals, amenities, recreation or any form of entertainment after work. Because the majority of workers are from developing countries, particularly from Asia, they are paid exploitative wages. These factors impact worker motivation and adherence to health and safety regulations on site.

Most workers live under horrible conditions off-site, cook low-qualitynutrient-poor meals and lack access to decent amenities. They lack recreation, entertainment and opportunities to broaden their horizons. In addition, because the vast majority of workers are poor Asians from third-world countries, they have low health and safety standards and pay, making it difficult to improve their fortunes.

A need exists for standards for worker accommodation, availability of cooked meals and recreation, as well as health and sanitation for off-site accommodations. It is possible to learn much from worker hostels operated by the more reputable United Kingdom and United States construction firms. 


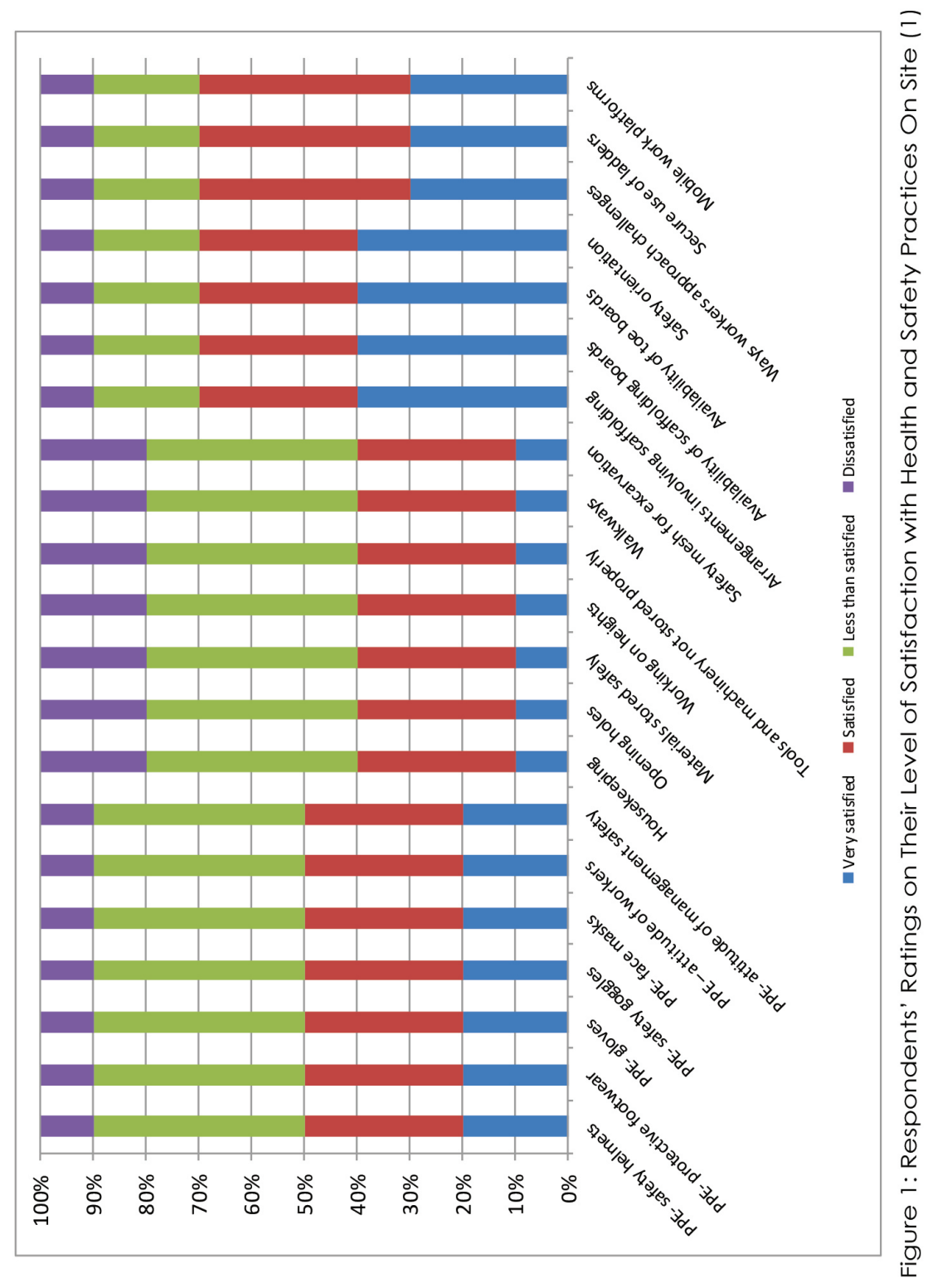

106/PENERBIT UNIVERSITI SAINS MALAYSIA 


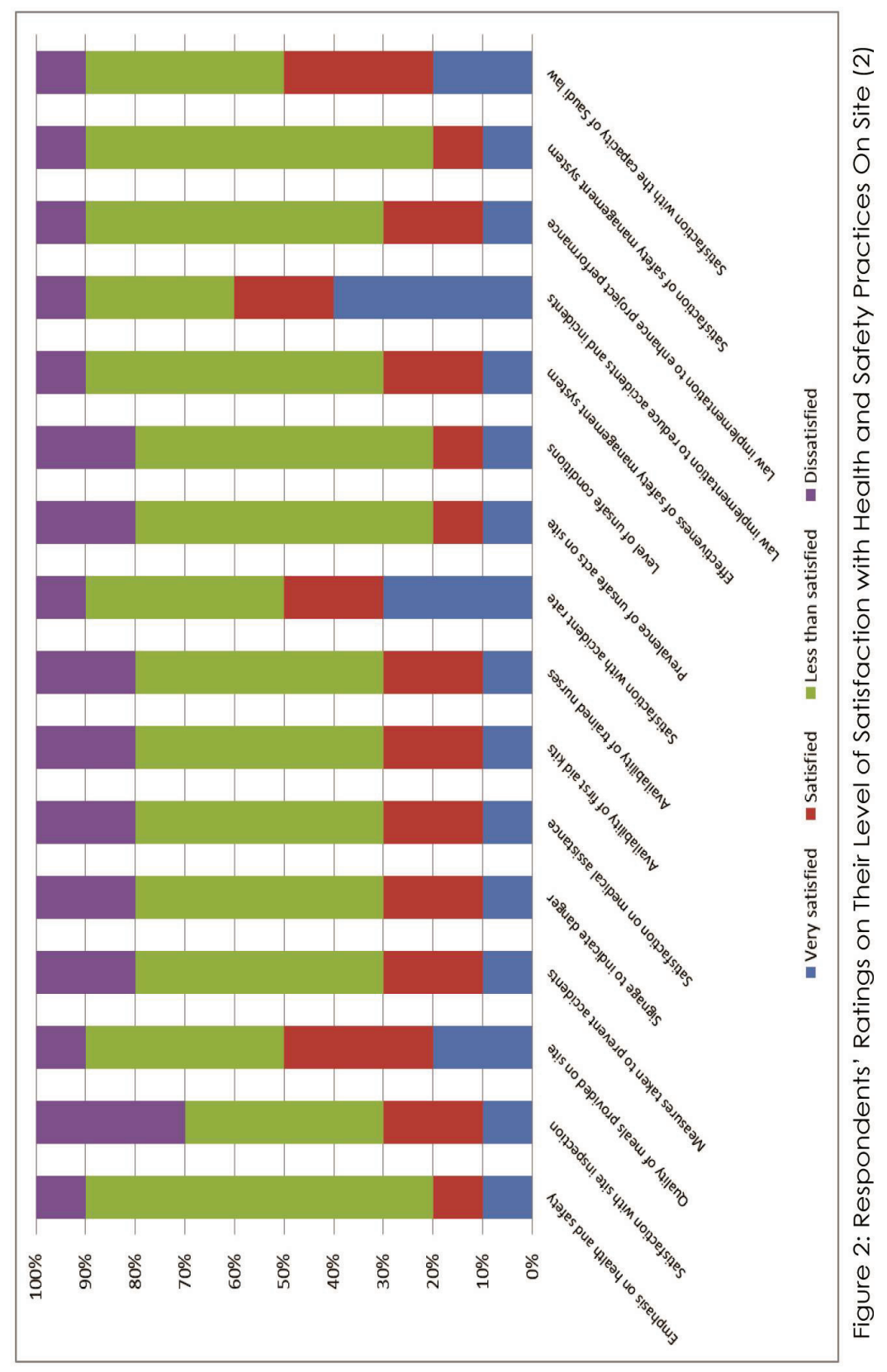

PENERBIT UNIVERSITI SAINS MALAYSIA/107 


\section{DISCUSSION OF FINDINGS}

Since $30 \%$ of respondents indicated that they rarely had health and safety officials and a further $20 \%$ indicated that they never had them, these responses support the notion that health and safety laws are existent but lack of enforcement. Even in the instances in which there were health and safety officials, some of them were not professionals, but were regular site workers who had to combine that role with other jobs. With $50 \%$ of the respondents less than satisfied or dissatisfied with their personal protective equipment, there is a possibility that employers are not adequately catering to the health and safety needs of their employees or following the health and safety procedures stipulated by Saudi Labour Law.

Sixty per cent were either less than satisfied or dissatisfied with practices such as housekeeping, material storage, working at heights and the provision of walkways. This also reinforces the assertion that health and safety practices are not enforced on construction sites. Sixty per cent were less than satisfied with the prevalence of unsafe acts on their construction site that could present dangers involving safety and health. The majority of respondents were less than satisfied with the effectiveness of the safety management system and the implementation of safety, health and labour standards of the Saudi Labour Law in increasing worker morale, worker awareness of site health and safety and improving worker behaviour. These findings contradict the role of health and safety as a means to address both physical and psychological well-being of workers on construction sites and other persons whose health is likely to be adversely affected by construction activities (Dryzek and Schlosberg, 2005).

It is surprising that $40 \%$ of the respondents were very satisfied while $30 \%$ were less than satisfied with the effectiveness of the safety management system at their construction site and with the implementation of Saudi Labour Law to reduce costs related to accidents. This contradicts the assertion that health and safety laws are typically not well implemented in Saudi Arabia.

The quality of the respondents' accommodations, meals and living conditions after work influence their work performance and attitudes. Most workers live under difficult conditions off-site, impacting their motivation and adherence to health and safety regulations on-site, which affects the dimension of employee involvement in the safety climate.

Improvements in health and safety in the construction industry will be possible only with the strict implementation of laws. It is not just health and safety laws that need strict enforcement but also laws related to commercial transactions, payments and the enforcement of contractual obligations. A culture of strict enforcement of the law will benefit the construction industry because cash flow will be available for timely payment and investment in a variety of needs, including health and safety. Construction firms must be held accountable to deliver on their contractual obligations.

Lewis and Thornbory (2010) and Kloss (2010) present a discussion about the implementation of health and safety at work in the United Kingdom. In the United Kingdom, the Health and Safety at Work Act of 1974 and regulations made under this Act, together with the Corporate Manslaughter and Corporate Homicide Act of 2007, the Regulatory Enforcement and Sanctions Act of 2008 and the Health and Safety Offences Act of 2008 give health and safety regulatory powers to the United Kingdom Health and Safety Executive. The Health and Safety at Work Act 
of 1974, and in particular the Construction Design and Management Regulation of 2015, addresses poor health and safety situations at a place of work. The main characteristic of this regulatory model is that the manner defining offences gives strict liability, and the approach taken for enforcement mainly about the benefit to the public, employees and employers. Strict liability only considers that death or injury has occurred without delving into matters related to the state of mind of an offender or other excuses. Hughes and Ferrett (2016) discuss the implications of an employer found guilty of maintaining poor health and safety conditions at work that result in the injury or death of an employee. The employer can expect to pay a hefty fine of up to $£ 20,000$ or face a 12-months imprisonment on summary conviction by a magistrate. An unlimited fine and 2-years imprisonment for directors found guilty of negligently inducing health and safety violations on indictment under the Health and Safety Offences Act of 2008 is an option for prosecutors. Should the Crown Prosecution Service consider a case serious enough to merit prosecution, the fines are unlimited, with stiff personal liability for those involved. Thus, there is no reason why Saudi Arabia construction industry will fail to implement health and safety regulations.

\section{CONCLUSIONS}

This study examined the concept and importance of health and safety in the construction industry in Saudi Arabia, including existing regulations, policies and measures, through a critical review of the literature. It investigated perceptions and attitudes regarding health and safety at Saudi Arabia construction sites through a questionnaire survey of 90 site workers and managers. Respondents were asked to rate their level of satisfaction with 37 health and safety practices at their construction sites. From the data, it was found that most respondents were either less than satisfied or dissatisfied with their health and safety provisions and practices. Many of the respondents did not have professional health and safety officials on their sites; some had non-professionals playing this role in addition to their site jobs. It was also found that the poor living conditions of workers off-site impact their health and safety performance on site.

Employers have a duty to ensure safe, stress-free and healthy work environments with competent health and safety officials on-site. They also have a duty to improve off-site conditions under which workers live, particularly if the employer is responsible for bringing migrant labour into Saudi Arabia. In general, the Saudi Arabia authorities have to ensure that the enforcement of safety regulations is more widespread.

This study is limited to the health and safety practices of the construction sector of Saudi Arabia. The participants were both managers and construction workers; however, the intention of the research was not to compare the two groups but to examine health and safety practices. A need exists to emphasise health and safety issues for the construction sector in Saudi Arabia due to increased demand for infrastructure throughout the country, guaranteeing the growth of the construction sector. 
As outcomes of the study, implications that can be made for health and safety management in the construction industry in Saudi Arabia are as follows:

- A need exists to improve the enforcement and implementation of Saudi Arabia health and safety laws, with better training of regulators and clear instructions to them about specific situations that cause violations of prevailing laws. Specified actions that are mandatory for regulators and inspectors under regulations of Saudi Arabia health and safety laws are necessary, and those that must regulate labour and labour conditions must receive rigorous training.

- Laws and regulations for maintaining the health, safety and standards for off-site worker accommodations or camps are necessary to improve living standards, which will help promote nutrition, mental contentment and commitment to work, productivity and progress on-site.

- A need exists to examine how best to improve the mental health of employees working in construction and other sectors of Saudi Arabia to ensure that they deliver productivity, progress and constant improvement.

- A need exists to improve commercial laws and the implementation of commercial laws in Saudi Arabia. This will encourage responsibility, capacity for timely recovery of cash flows and stability in all sectors. When financial planning and financial engineering present less uncertainty due to the implementation of laws, it is likely that employers will have the funds to pay for the health, safety and welfare of employees.

\section{REFERENCES}

Baig, M.M. (2001). Safety Assessment in Industrial Construction Projects in Saudi Arabia. Dhahran: King Fahd University of Petroleum and Minerals. Available at: http://www.google.co.uk/urlesa=t\&source=web\&cd=2\&ved =0CCOQFjAB\&url=http\%3A\%2F\%2Fwww.kfupm.edu.sa\%2Flibrary\%2Flibdow nloads\%2F1 402842.pdf\&ei=OVR7TdjaKMXVrQfW5MmzBQ\&usg=AFQjCNEYC mDGWBsVxOVTLbQBLMZ6XogqFW [Accessed on 12 August 2013].

Brown, R.L. and Holmes, H. (1986). The use of a factor-analytic procedure for assessing the validity of an employee safety climate model. Accident Analysis \& Prevention, 18(6): 455-470. https://doi.org/10.1016/0001-4575 (86)90019-9.

Bryman, A. (2012). Social Research Methods. 4th Ed. Oxford, UK: Oxford University Press.

Bryman, A. and Bell, E. (2011). Business Research Methods. 3rd Ed. Oxford, UK: Oxford University Press.

Coble, R.J., Haupt, T.C. and Hinze, J. (eds.). (2000). The Management of Construction Safety and Health. London: Taylor \& Francis.

Cole, R.J. and Lorch, R. (2003) Buildings, Culture and Environment: Informing Local and Global Practices. Oxford, UK: Blackwell Publishing. https://doi.org/ $10.1002 / 9780470759066$.

Cooper, M.D. and Phillips, R.A. (2004). Exploratory analysis of the safety climate and safety behavior relationship. Journal of Safety Research, 35(5): 497512. https://doi.org/10.1016/j.jsr.2004.08.004.

110/PENERBIT UNIVERSITI SAINS MALAYSIA 
Coyle, I.R., Sleeman, S.D. and Adams, N. (1995). Safety climate. Journal of Safety Research, 26(4): 247-254. https://doi.org/10.1016/0022-4375(95)00020-Q.

Creative Research Systems. (2011). Sample Size Calculator, Creative Research Systems. Available at: http://www.surveysystem.com/sscalc.htm\#one [Accessed 14 August 2013].

Creswell, J.W. (2014). Research Design Qualitative, Quantitative, and Mixed Methods Approaches. 4th Ed. Thousand Oaks, CA: SAGE Publications.

Dattalo, P. (2008). Determining Sample Size: Balancing Power, Precision and Practicality. Oxford, UK: Oxford University Press. https://doi.org/10.1093/ acprof:oso/9780195315493.001.0001.

Davies, F., Spencer, R. and Dooley, K. (2001). Summary Guide to Safety Climate Tools. Norwich: HSE Books.

Dedobbeleer, N. and Béland, F. (1991). A safety climate measure for construction sites. Journal of Safety Research, 22(2): 97-103. https://doi.org/10.1016/ 0022-4375(91)90017-P.

Dryzek, J.S. and Schlosberg, D. (2005). Debating the Earth: The Environmental Politics. Oxford, UK: Oxford University Press.

Farooqui, R.U., Arif, F. and Rafeeqi, S.F.A. (2008). Safety performance in construction industry of Pakistan. First International Conference on Construction in Developing Countries (ICCIDC-I) "Advancing and Integrating Construction Education, Research \& Practice." Karachi, Pakistan, 4-5 August. Available at: http://civil.neduet.edu.pk/ICCIDCI/Conference\%20Proceedings/Papers/009.pdf [Accessed on 12 September 2013].

Findouter.com (2010). Construction in Saudi Arabia, Middle East. Available at: http://www.findouter.com/MiddleEast/Saudi_Arabia/Business_and_Econo my/Services/Construction [Accessed on 12 August 2013].

Flin R., Mearns, K., O'Connor, P. and Bryden, R. (2000). Measuring safety climate: identifying the common features. Safety Science, 34(1-3): 177-192. https://doi.org/10.1016/S0925-7535(00)00012-6.

Guldenmund, F.W. (2000). The nature of safety culture: A review of theory and research. Safety Science, 34(1-3): 215-257. https://doi.org/10.1016/S0925$7535(00) 00014-X$.

Gulf Talent. (2008). Saudi Labour Law. Available at: http://docs.docstoc.com/orig/ 292894/a2ad4070-6bce-4d0c-bead-3ccb3f4a9lab.pdf [Accessed on 14 August 2013].

Hahn, S.E. and Murphy, L.R. (2008). A short scale for measuring safety climate. Safety Science, 46(7): 1047-1066. https://doi.org/10.1016/j.ssci.2007.06.002.

Hughes, P. and Ferrett, E. (2016). An Introduction to Health and Safety in Construction. 5th Ed. Butterworth-Heinemann: Elsevier.

IHS Construction Solutions. (2007). Saudi Arabia to Base Building Code on I-Codes, IHS Construction Solutions. Available at: https://www.ihs.com/products/ standards-codes-specs.html [Accessed on 11 July 2013].

Jannadi, O.M. and Al-Sudairi, A. (1995). Safety management in the construction industry in Saudi Arabia. Building Research and Information, 23(1): 60-63. https://doi.org/10.1080/09613219508727425.

Jannadi, O.M. and Assaf, S. (1998). Safety assessment in the built environment of Saudi Arabia. Safety Science, 29(1):15-24. https://doi.org/10.1016/S09257535(98)00018-6. 
Jannadi, O.M. and BU-Khamsin, M.S. (2002). Safety factors considered by industrial contractors in Saudi Arabia. Building and Environment 37(5): 539-547. https://doi.org/10.1016/\$0360-1323(01)00056-7.

Kartam, N.A. (1997). Integrating safety and health performance into construction CPM. Journal of Construction Engineering and Management, 123(2): 121126. https://doi.org/10.1061/(ASCE)0733-9364(1997)123:2(121).

Kloss, D. (2010). Occupational Health Law. 5th Ed. London: Wiley-Blackwell. https://doi.org/10.1002/9781444319712.

Lewis, J. and Thornbory, G. (2010). Employment Law and Occupational Health: A Practical Handbook. London: Wiley Publishing. https://doi.org/10.1002/ 9781444320480.

Li, R.Y.M. and Poon, S.W. (2010). The evolution of construction accident causation models. Proceedings of W099: Special Track 18th CIB World Building Congress Salford, United Kingdom, 253-264. Available at: http://cibworld.xs4all.nl/dl/publications/w099_pub357.pdf [Accessed on 15 August 2013].

Middle East Info. (2011). Saudi Arabia: Basic Law of Government. Available at: http://www.mideastinfo.com/documents/Saudi_Arabia_Basic_Law.htm [Accessed on 14 September 2013].

Ministry of Labour, Kingdom of Saudi Arabia. (2011). Labour Law of the Kingdom of Saudi Arabia. Available at: http://mol.gov.sa/en/Pages/LaborLaw .aspx? $\mathrm{m}=3$ [Accessed on 9 July 2013].

Mohamed, S. (2002). Safety climate in construction site environments. Journal of Construction Engineering and Management, 128(5): 375-384. https://doi.org/10.1061/(ASCE)0733-9364(2002) 128:5(375).

Neale, R. and Waters, J. (2012). Safety and health in construction in developing countries: The humanitarian paradox. In G. Ofori (eds.). Contemporary Issues in Construction in Developing Countries. New York: Spon Press, 144188.

O'Kane, M. (2010). Saudi Arabia Labour Law Outline. Sharjah, UAE: Al-Andalus Publishing.

Ramady, M.A. (2010). The Saudi Arabian Economy: Policies, Achievements and Challenges. New York: Springer Science \& Business Media. https://doi.org/ 10.1007/978-1-4419-5987-4.

Saudi Ministry of Labour. (2000). Labour Law of the Kingdom of Saudi Arabia. Kingdom of Saudi Arabia: Ministry of Labour. Available at: http://mol.gov.sa/en/Pages/LaborLaw.aspx?m=3 [Accessed on 9 July 2013].

Saunders, M., Philip, L. and Thornhill, A. (2012). Research Methods for Business Students. 6th Ed. London: Financial Times Prentice Hall.

Seo, D., Torabi, M., Blair, E. and Ellis, N. (2004). A cross-validation of safety climate scale using confirmatory factor analytic approach. Journal of Safety Research, 35(4): 427-445. https://doi.org/10.1016/j.jsr.2004.04.006.

Williamson, A.M., Feyer, A., Cairns, D. and Biancotti, D. (1997). The development of a measure of safety climate: The role of safety perceptions and attitudes. Safety Science, 25(1-3): 15-27. https://doi.org/10.1016/S0925-7535 (97)00020-9. 
Wilson, J. (2010). Essentials of Business Research: A Guide to Doing Your Research Project. London: SAGE Publications.

World Law Guide. (2010). Legislation Saudi Arabia. Available at: http://www. lexadin.nl/wlg/legis/nofr/oeur/lxwesau.htm [Accessed on 14 August 2013].

Yi-man, Li. (2006). Effectiveness of Various Construction Safety Measures in Hong Kong. Hong Kong: University of Hong Kong. Available at: https://hub.hku.hk/handle/10722/48903 [Accessed on 19 July 2013].

Zikmund, W.G. (2000). Business Research Methods. 6th Ed. Orlando: Harcourt.

Zohar, D. (1980). Safety climate in industrial organizations: Theoretical and applied implications. Journal of Applied Psychology, 65(1): 96-102. https://doi.org/ 10.1037/0021-9010.65.1.96.

Zohar, D. (2010). Thirty years of safety climate research: Reflections and future directions. Accident Analysis \& Prevention, 42(5): 1517-1522. https://doi.org/10.1016/j.aap.2009.12.019.

Zohar, D. and Luria, G. (2005). A multilevel model of safety climate: Cross-level relationships between organization and group-level climates. Journal of Applied Psychology, 90(4): 616-628. https://doi.org/10.1037/00219010.90.4.616.

Zou, P.X.W. and Sunindijo, R.Y. (2010). Construction safety culture: A revised framework. Paper presented at the 15th annual symposium of Chinese Research Institute of Construction Management (CRIOCM), Johor Bahru, Malaysia, 6-8 August. 